\title{
Commentary to ‘Outcomes of Seromuscular Bladder Augmentation versus Standard Ileocystoplasty: A Single Institution Experience over 14 years'
}

\author{
Martin Kaefer
}

The technique of seromuscular bladder augmentation (SMBA), as first described experimentally by Shoemaker [1] and later popularized in human subjects by Dewan [2], continues to hold great interest among urologists as a means of providing an augmentation substrate that avoids incorporation of absorptive epithelium. Yet the widespread acceptance of this technique has remained elusive, due to lack of evidence that a significant decrease in complication rate exists that would warrant the increased technical challenges and length of the operative procedure. To this end, the authors of the present paper seek to document differences between augmentation with unaltered ileal and demucosalized colonic segments.

While this report lends further support to SMBA being a safe and effective technique, the results presented show no advantage over standard enterocystoplasty. The small number of subjects in the SMBA group $(\mathrm{n}=10)$ does not provide sufficient power to demonstrate a statistically significant difference in the categories investigated. The authors point to more stones being formed in the ileocystoplasty group (8/30 or 27\%) relative to the SMBA cohort. However, from the results section, one gleans that only five of the stones were of significant size to require surgical intervention. If only 5/30 (17\%) patients had significant stones, the calculated P -value between the SMBA and ileocystoplasty groups would be $\mathrm{P}=0.17$. Compared to the historical results of Jednak, et al, who found that $6 \%$ of his cohort of 32 SMBA patients developed calculi [3], the difference between the two groups becomes even smaller.

Despite the fact that significant differences in stone formation cannot be demonstrated, I remain a strong supporter of this and other alternatives to standard bladder augmentation. The theory behind the

This is the author's manuscript of the article published in final edited form as:

Kaefer, M. (2017). Commentary to “Outcomes of Seromuscular Bladder Augmentation versus Standard Ileocystoplasty: A Single Institution Experience over 14 years.” Journal of Pediatric Urology, 13(2), 201. https://doi.org/10.1016/j.jpurol.2016.05.030 
present procedure is sound and worthy of continued pursuit. Perhaps with time we will find that the difference in stone incidence is statistically significant or the probability of malignant transformation is less. However, if we are to come to any meaningful conclusions that the demucosalization technique is equally good at achieving an increase in bladder capacity while limiting complications, it would be beneficial for future studies to focus not on differences between two different bowel segments (demucosalized colon versus unaltered ilium) but rather between two segments of equal composition (demucosalized colon versus unaltered colon). 


\section{References}

[1]. Shoemaker W.C., and Marucci H.D.: The experimental use of seromuscular grafts in bladder reconstruction; preliminary report. J Urol 1955 Feb; 73: pp. 314-321

[2]. Dewan P.A.: Augmentation colocystoplasty. Pediatr Surg Int 1994; 9: pp. 526-810

[3]. Jednak R., Schimke C.M., Barroso U.J.R., Barthold J.S., and González R.: Further experience with seromuscular colocystoplasty lined with urothelium. J Urol 2000 Dec; 164: pp. 2045-2049 